\title{
Partidos políticos e grupos de interesse: definições, atuação e vínculos
}

\author{
Wagner Pralon Mancuso
}

\section{Resumo}

Partidos políticos e grupos de interesse são instrumentos de mediação entre a sociedade e o Estado que estão presentes em todas as democracias contemporâneas. Este artigo sugere respostas para três questões: i) qual é a natureza específica dessas organizações?; ii) que atividades políticas elas desempenham? e iii) que tipo de interrelações elas mantêm entre si? A resposta para a última questão no cenário brasileiro seria decisivamente favorecida pela regulamentação do lobbying e pelo aperfeiçoamento da legislação sobre financiamento de campanhas eleitorais.

O objeto deste artigo são os partidos políticos e os grupos de interesse. Esses dois tipos de organização são elementos característicos dos sistemas políticos democráticos contemporâneos, nos quais são tidos como instrumentos de mediação entre a sociedade e o Estado.

$\mathrm{O}$ artigo procura na literatura da ciência política as respostas para três questões.

A primeira se refere à natureza específica de cada uma das organizações. Enfim, em que pensam os cientistas políticos quando falam em partidos? O que entendem por grupos de interesse? Existe um acordo mínimo no que tange à forma de conceber essas organizações políticas? Quais são os aspectos mais controvertidos desse problema? 
A segunda questão é relativa às atividades que são tipicamente atribuídas às duas organizações. Que atividades são essas? Elas são efetivamente desempenhadas pelos partidos e pelos grupos de interesse? Há algo que realmente difere a atuação dos dois tipos de agrupamento? Em que pontos a ação deles pode coincidir?

Finalmente, a terceira questão diz respeito à relação das organizações entre si. Por que meios os grupos de interesse e os partidos políticos tradicionalmente se vinculam? A relação entre eles é simétrica ou assimétrica? De que forma a ciência política no Brasil lida com esse tema?

\section{Definições}

Os partidos políticos podem ser definidos de duas maneiras uma mais abrangente, outra menos abrangente (Nicolau, 1996: 9-11).

Conforme a definição ampla, um partido político pode ser entendido simplesmente como "uma organização que tem por objetivo colocar seus representantes no governo". Essa descrição abarca todos os tipos de partidos: aqueles que disputam eleições em países democráticos (ou seja, que procuram colocar seus representantes no governo pela via competitiva), os partidos únicos (que proíbem a competição eleitoral e impõem seus representantes no poder) e os partidos anti-sistema (que não se preocupam em vencer as eleições, mas em conquistar o poder por outros meios, eventualmente pela força).

Outra definição de partido político é a definição restrita, que se aplica apenas aos partidos que atuam em sistemas políticos democráticos.

Vários autores importantes no âmbito da ciência política adotam essa concepção reduzida. É o caso, por exemplo, de Epstein (1982: 9), para quem um partido político é qualquer grupo que procura angariar votos para que determinados indivíduos sejam eleitos - sob sua sigla para ocupar cargos públicos. Sartori (1982: 85-6) também define partido político por sua atividade no contexto eleitoral, pois, para ele, "um partido é qualquer grupo político identificado por uma sigla oficial que apresenta em eleições, e seja capaz de colocar através de eleições (livres ou não), candidatos a cargos públicos". Panebianco (1990: 34) é 
outro autor que distingue os partidos das demais organizações presentes nos sistemas políticos a partir do ambiente em que aqueles desenvolvem suas atividades específicas: a arena eleitoral, na qual competem por votos.

Pelo acima exposto, não é incorreto afirmar que parece haver um consenso mínimo entre estudiosos dos partidos políticos em torno do conceito restrito de seu objeto de estudo: partidos políticos são organizações que competem por votos nas eleições (Nicolau, 1996: 10).

Assim como no caso dos partidos políticos, também há definições abrangentes e definições reduzidas de grupo de interesse.

Almond \& Powell Jr. (1972: 53), por exemplo, apresentam uma definição ampla. Para esses autores, um grupo de interesse é qualquer "grupo de indivíduos ligados por laços particulares de preocupações ou de vantagens e que têm certa consciência desses laços". Em função de sua abrangência, essa concepção inclui todos os tipos de grupos de interesse, independentemente das atividades que realizam, de seu grau de organização e das clivagens a partir das quais se constituem (étnica, regional, classista, profissional, dentre outras).

Vários autores, no entanto, preferem trabalhar com concepções mais restritas. Em síntese, essas concepções restritas focalizam somente os grupos que apresentam demandas ao poder público. ${ }^{2}$

De acordo com Salisbury (1977: 175), a definição restrita de grupo de interesse presente de forma implícita ou explícita na literatura específica sobre o tema é a seguinte: "grupo de interesse é uma associação formalmente organizada que se dedica à realização de atividades que visam a influenciar as decisões a serem tomadas pelas autoridades governamentais". Wootton (1972: 41), por sua vez, define grupo de interesse como "um ator particular, diferente de um partido político, que tenta influenciar um alvo público para atingir algum objetivo". Embora expressa em termos bastante diversos, a definição de grupo de interesse apresentada por Wootton é, em essência, semelhante à de Salisbury. Há duas diferenças de menor relevância entre elas. Em

1 Na mesma linha de Almond \& Powell Jr., Robert Salisbury (1977: 191), importante estudioso dos grupos de interesse norte-americanos, afirma que a opinião de que todos os grupos são formados para influenciar as ações governamentais representa "uma grande violência aos fatos históricos e leva a equívocos importantes na compreensão do fenômeno dos grupos de interesse". 
primeiro lugar, Wootton enfatiza a diferença entre grupo de interesse e partido político. Em segundo lugar, Wootton não exige - ao contrário de Salisbury - que o grupo de interesse seja uma associação formalmente organizada.

É importante destacar que alguns autores optam por utilizar a expressão grupos de pressão no lugar de grupos de interesse, incorporando ao próprio conceito a atividade que caracteriza os grupos.

Key (1944: 213) é um desses autores. Para Key, os grupos de pressão são grupos que se empenham pela adoção - ou pela rejeição de políticas públicas que afetem os seus interesses. Meynaud (1960: 44-5) também utiliza a expressão grupos de pressão, que ao seu ver designa órgãos estranhos à máquina governamental propriamente dita que, desde o exterior, efetuam ações sobre as autoridades habilitadas pela Constituição - ou por qualquer outro dispositivo regulamentar para preparar, suspender e executar decisões. Ao contrário de vários autores (por exemplo: Wootton e Almond \& Powell Jr.), Meynaud não considera os grupos que fazem parte da "máquina governamental" burocracia, gabinete de ministros, etc. - como possíveis grupos de pressão. Pasquino (1982: 11) define grupo de pressão como uma organização que procura, "através do uso de sanções (negativas - punições- ou positivas - prêmios) ou da ameaça do uso delas, influenciar sobre decisões que são tomadas pelo poder político, seja a fim de manter a distribuição prevalecente de bens, serviços, honras e oportunidades, seja a fim de conservá-la frente às ameaças de intervenção - de outros grupos ou do próprio poder político".

Salisbury (1977: 176) prefere a expressão grupo de interesse à expressão alternativa grupo de pressão por dois motivos: i) porque pressão é um termo com forte conotação negativa e ii) porque pressão pressupõe uso de sanções nas relações do grupo com o poder público, o que nem sempre ocorre.

Não obstante as pequenas diferenças - de conteúdo ou de terminologia - existentes entre as definições, os estudiosos dos grupos de interesse também parecem partilhar de um consenso mínimo no que tange ao conceito restrito de seu objeto: grupos de interesse (ou de pressão) são entidades diferentes de partidos políticos que entram em contato com os decision-makers do poder público para influir em suas decisões. 


\section{Funções, semelhanças e diferenças}

O critério utilizado por Almond \& Powell Jr. (1972) para caracterizar a atuação dos grupos de interesse e dos partidos políticos é o critério da amplitude das atividades das organizações.

De acordo com esses autores, a articulação de interesses é a função política tipicamente desempenhada pelos grupos de interesse, podendo ser definida (1972: 52) como "o processo pelo qual os grupos apresentam demandas aos tomadores de decisões políticas".

$\mathrm{O}$ fato de que os grupos de interesse tradicionalmente realizam a função de articulação não significa, no entanto, que essa é uma função exclusiva de tais grupos. Ao discutirem a questão das funções executadas pelos partidos políticos, os autores consideram que a articulação de interesses também é uma atividade exercida por eles. Sartori (1982) concorda com Almond \& Powell Jr. ao afirmar que os partidos são agências que exprimem para o governo as reivindicações e os desejos do povo. O mesmo se pode dizer de Bonavides (1983: 538), para quem "o partido político, do mesmo modo que o grupo de pressão, conduz os interesses de seus membros até as regiões do poder aonde vão em busca de uma decisão política favorável".

Segundo Almond \& Powell Jr., os partidos também realizam outras atividades além da articulação de interesses, tais como a agregação de interesses (a transformação das demandas de segmentos específicos da sociedade em alternativas política gerais), o recrutamento de candidatos que pretendem ocupar cargos públicos e a socialização política dos membros. ${ }^{3}$

Gianfranco Pasquino (1982: 12) se aproxima de Almond \& Powell Jr. ao corroborar a idéia de que a articulação de interesses é uma função que pode ser desempenhada tanto pelos partidos políticos quanto pelos grupos de interesse e que, portanto, não é o que distingue a atividade dos dois tipos de organização. No entanto, Pasquino se afasta daqueles autores ao afirmar que os partidos nem sempre exercem o papel de agregar interesses sociais. Pasquino recorda que os partidos

3 Epstein (1982: 77) acrescentaria como função específica dos partidos políticos a estruturação do voto, ou seja, o fornecimento aos eleitores de uma base para a sua opção eleitoral (por meio, por exemplo, da apresentação de plataformas políticas). 
políticos podem representar os interesses de setores sociais estreitos, apresentando perspectivas muito parciais. É o que Dobrowolski (1985: 241) também sustenta, ao lembrar que os partidos políticos, às vezes, se apresentam como promotores dos interesses de uma classe determinada ou como portadores de uma ideologia específica (é o caso dos partidos proletários e dos partidos religiosos, por exemplo). Por outro lado, há muitos grupos de interesse que afirmam pugnar por objetivos amplos e variados (por exemplo: grupos feministas, grupos ecologistas, grupos de defesa dos direitos dos consumidores, entre outros).

Segundo Pasquino, há vários outros princípios que são tão inadequados quanto a díade articulação/agregação para diferenciar os partidos políticos dos grupos de interesse. $\mathrm{O}$ autor considera incorreto, por exemplo, afirmar que os partidos se distinguem dos grupos de interesse porque suas atividades são contínuas, ao passo que as atividades dos grupos de interesse são intermitentes. De fato, muitos grupos de interesse também atuam de forma contínua. Outras formas equivocadas de distinguir partidos políticos e grupos de interesse são aquelas que remontam à dimensão das organizações (assim como há partidos políticos que são maiores que certos grupos de interesse, também há grupos de interesse que são maiores que certos partidos políticos). Ou ao âmbito em que elas atuam (da mesma forma que existem grupos de interesse locais e partidos políticos de caráter nacional, também há grupos de interesse de abrangência nacional e partidos políticos de atuação localizada ou regionalizada).

Para Pasquino - e para outros autores que o acompanham nesse ponto, tais como Key (1940: 209-13) e Meynaud (1960: 45) - a distinção entre os partidos políticos e os grupos de interesse reside no fato de que as primeiras organizações possuem duas funções exclusivas: a disputa eleitoral e a gestão direta do poder público. Assim, os partidos políticos são organizações que participam diretamente da arena eleitoral e que procuram, por esse meio, ascender à arena decisória, na qual as políticas públicas são formuladas e implementadas. Por outro lado, os grupos de interesse são organizações que não disputam eleições mas cujas atividades visam a interferir em decisões do poder público que lhes dizem respeito.

O conjunto de agências que podem tornar-se alvos das atividades dos grupos de interesses é muito diversificado. Algumas vezes os alvos escolhidos são organismos internacionais tais como a União Euro- 
péia (Graziano, 1997; Egdell \& Thomson, 1999). Outras vezes os alvos visados são setores da administração pública de nível nacional ou infranacional (Galaskiewicz, 1981; Chubb, 1983; Pika, 1983; Heinz et alli, 1993; Thomas \& Hrebrenar, 1999). A ação das entidades também é dirigida com freqüência para organismos legislativos (Longley, 1967; Smith, 1984 e 1995; Wright, 1990; Tierney, 1992; Diana Evans, 1996; Diniz \& Boschi, 1997 e 2000; Aragão, 1994, 1996 e 2000) e para órgãos reguladores de serviços públicos concedidos à iniciativa privada (Furlong, 1997; Figueiredo \& Tiller, 1999).

As decisões políticas que provocam a ação dos grupos de interesse podem ser tomadas no âmbito de uma única agência ou podem ser descentralizadas, envolvendo várias agências diferentes (a tramitação de um projeto de lei federal, por exemplo, envolve a Câmara dos Deputados, o Senado Federal e a Presidência da República). Em ambos os casos os grupos de interesse podem começar a atuar desde os momentos que antecedem o estágio deliberativo, tais como a) o momento da definição das questões que irão compor a agenda das agências, b) o momento da redação de projetos e c) o momento de debate e de negociação em torno dos projetos existentes. As atividades de articulação também podem ocorrer durante o momento deliberativo propriamente dito. As atividades podem ocorrer ainda nas fases do processo decisório que eventualmente sucedem o estágio deliberativo, tais como a fase de regulamentação das decisões tomadas e a fase de avaliação $e$ de revisão das decisões.

Como enfatiza Mansbridge (1992), o caráter das atividades dos grupos de interesse não é algo que possa ser definido de antemão. Os grupos podem, por exemplo, dirigir suas atividades para a extração de rendas (rent-seeking). Agindo assim, esses grupos utilizam "o poder que obtêm a partir de sua capacidade de organização e de suas fontes de financiamento para extrair do tesouro público benefícios que serão distribuídos para seus dirigentes, funcionários e membros". O efeito dessas atividades tende a ser socialmente deletério. Outros grupos, no entanto, podem fornecer informações e idéias para os tomadores de decisão durante o processo deliberativo, na expectativa de que as soluções encontradas sejam as melhores possíveis para todos. Nesse caso, o efeito das atividades dos grupos de interesse pode ser socialmente positivo.

Há grupos de interesse cuja finalidade principal é a obtenção de vantagens materiais para seus membros. No entanto, o auto-interesse 
material nem sempre é o fator determinante (Orren, 1988). De fato, a atuação política de várias entidades é motivada a) por convicções ideológicas (por exemplo: o Instituto Liberal ${ }^{4}$ e os grupos que apóiam ou combatem a pena de morte e o aborto), b) por princípios religiosos (por exemplo: Conferência Nacional dos Bispos do Brasil - CNBB e Conselho Nacional das Igrejas Cristãs no Brasil - CONIC), c) pela defesa do interesse público (por exemplo: entidades ambientalistas, entidades de defesa dos direitos do consumidor, entidades de combate à corrupção na política e entidades de defesa dos direitos humanos), d) pela defesa de segmentos sociais específicos (por exemplo: grupos indigenistas, grupos de apoio a portadores de deficiências ou doenças graves, grupos de amparo a crianças carentes, dentre outros) ou ainda por outros fatores. Com muita freqüência as entidades são impulsionadas por motivações simultâneas de natureza diversa.

\section{Inter-relações}

As duas seções anteriores deste trabalho focalizaram os partidos políticos e os grupos de interesse em suas especificidades. Nesta seção o foco será deslocado para as relações que os dois tipos de organização mantêm entre si.

De acordo com Almond (1957: 277) e Dobrowolski (1985: 244), o vínculo entre partidos políticos e grupos de interesse - caso exista pode assumir formas diversas, tais como: i) filiação simultânea (que ocorre quando um mesmo indivíduo faz parte, ao mesmo tempo, do conjunto de membros das duas organizações); ii) intercâmbio de informações (por exemplo: um grupo de interesse pode apresentar propostas e estudos a um partido político e receber notícias sobre a tramitação de projetos de lei de seu interesse), iii) partilha de posições ideológicas comuns e iv) fluxo de recursos materiais (do grupo de interesse para o partido político e/ou do partido para o grupo).

4 De acordo com Gros (1993), o primeiro núcleo do Instituto Liberal foi criado em 1983, no Rio de Janeiro, por um pequeno grupo de grandes empresários. Dez anos após, em 1993, já existiam nove institutos em funcionamento em todo o país. O principal objetivo dos institutos é divulgar a ideologia liberal entre as elites do país. 
O tema da relação entre partidos e grupos de interesse também foi abordado por Panebianco (1990: 328-32). De acordo com Panebianco, a relação que um partido político mantém com um grupo de interesse pode assumir três configurações distintas: domínio, subordinação $e$ intercâmbio equilibrado.

A relação de domínio ocorre quando a liderança do grupo de interesse depende dos recursos oriundos do partido político (recursos financeiros e/ou simbólicos) para manter sua organização e quando não há dependência no sentido inverso. Nesse caso, como sustenta Pasquino (1982: 13), o grupo de interesse dominado não pode usufruir de autonomia para realizar suas atividades.

Na relação de subordinação acontece o contrário. Agora o partido político depende dos recursos proporcionados pelo grupo de interesse e o grupo de interesse não precisa dos recursos disponibilizados pelo partido político. Quem padece de heteronomia é a liderança do partido, pois a liderança do grupo de interesse possui condições para interferir de forma decisiva no recrutamento dos candidatos, na definição das propostas políticas que o partido irá defender e em vários outros aspectos da vida partidária. O partido político torna-se um mero porta-voz das demandas particulares dos grupos de interesse.

No caso do intercâmbio equilibrado as cúpulas das duas organizações necessitam dos recursos provenientes da outra parte. É o que ocorre, segundo Panebianco, quando "o partido necessita dos recursos financeiros do grupo e o grupo necessita do apoio do partido para obter medidas legislativas favoráveis". Ao contrário dos demais tipos de relação, a relação de intercâmbio equilibrado é "honrosa" para ambas as partes.

É importante sempre ter em mente que a natureza das ligações de fato existentes entre partidos políticos e grupos de interesse não pode ser estabelecida a priori, mas apenas mediante análises empíricas rigorosas.

A relação entre partidos políticos e grupos de interesse é um assunto pouco explorado pela ciência política brasileira. A escassez de trabalhos nessa área possivelmente está associada à pobreza dos dados empíricos disponíveis. Essa pobreza pode ser explicada, em grande parte, por dois fatores. Por um lado, uma parcela significativa dos grupos de interesse brasileiros (sindicatos, federações, confederações, 
centrais sindicais, em suma, todas as entidades que compõem o sistema corporativo oficial de representação de interesses de trabalhadores e de empresários) está legalmente proibida de destinar contribuições financeiras para os partidos políticos. Por outro lado, as informações referentes às contribuições de campanha e consignadas nas prestações de conta enviadas pelos partidos políticos aos Tribunais Eleitorais são pouco confiáveis.

Um dos poucos textos que lidam com o tema é o artigo de Kinzo (1997).

Segundo a autora, os partidos políticos brasileiros não são identificados claramente com grupos de interesse específicos. Segmentos sociais importantes têm seus interesses representados no Congresso Nacional por agrupamentos suprapartidários. Kinzo cita o exemplo dos grandes produtores rurais, cujos interesses são defendidos pela "bancada ruralista", formada por membros de doze partidos na Câmara dos Deputados e por membros de seis partidos no Senado Federal (partidos de centro-esquerda, centro, centro-direita e direita). Outros exemplos que não estão presentes no texto apóiam a afirmação da autora, como os casos da bancada nacionalista ou da bancada evangélica, entre outras.

A falta de identificação entre partidos políticos e grupos de interesse leva as empresas privadas - principais financiadoras de campanhas no Brasil - a distribuir suas doações para candidatos de partidos situados ao longo de todo o espectro ideológico. A distribuição não é simétrica, no entanto, pois beneficia, principalmente, os candidatos com mais chances de vitória (de acordo com as pesquisas de opinião) e os candidatos cujas plataformas políticas agradam mais ao empresariado.

É freqüente encontrar-se na imprensa a notícia de que o Congresso Nacional voltou a considerar a possibilidade de aprovar uma lei que regulamente a atividade de lobby no Brasil. ${ }^{5}$ Um projeto nesse sentido, de autoria do atual Vice-Presidente da República, Marco Maciel, está engavetado na Câmara dos Deputados há mais de dez anos, desde 1989.

Entre outras coisas, o projeto i) cria a exigência de registro para o lobista que atua no Congresso Nacional; ii) obriga o lobista a prestar

5 Por exemplo, O Estado de São Paulo, "Regulamentação do lobby tem apoio de líderes no Congresso", 23/08/2000. 
conta periodicamente dos gastos referentes à sua atuação dentro $e$ fora da Câmara e do Senado; iii) obriga o lobista a informar quem é o seu contratante e que projeto está acompanhando e iv) estabelece punições para os casos de desobediência às regras.

A aprovação de uma lei do lobbying lançaria muita luz sobre o problema da ligação entre os grupos de interesse e os membros dos partidos políticos que atuam na arena decisória do Poder Legislativo Federal.

Além disso, a legislação sobre financiamento de campanhas eleitorais precisa ser aperfeiçoada, para que as informações sobre as fontes de apoio financeiro dos partidos políticos se tornem mais completas e precisas.

\section{Referências bibliográficas}

Almond, Gabriel A. Research note: a comparative study of interest groups and the political process. American Political Science Review, 1957.

.; Powell JR., G. Bingham. Uma teoria de política comparada. Rio de Janeiro: Zahar Editores, 1972.

Aragão, Murillo de. Grupos de pressão no congresso nacional: como a sociedade pode defender licitamente seus direitos no poder legislativo. São Paulo: Maltese, 1994.

. A ação dos grupos de pressão nos processos constitucionais recentes no Brasil. Revista de Sociologia e Política. n. 6/7, Universidade Federal do Paraná, Curitiba, 1996.

. Brasil e Argentina: abordagem comparada sobre grupos de pressão no poder legislativo. Brasília, 2000. Tese (Doutorado) - Centro de Pesquisa e Pós-Graduação sobre a América Latina e Caribe, Universidade de Brasília.

Bonavides, Paulo. Ciência Política. Rio de Janeiro: Editora Forense, 1983.

CHUBB. Interest groups and the bureaucracy: the politics of energy. Stanford University Press, 1983

DINIz, Eli; BoschI, Renato. O legislativo como arena de interesses organizados: a atuação dos lobbies empresariais. Artigo não publicado. 1997.

Globalização, herança corporativa e a representação dos interesses empresariais: novas configurações no cenário pós-reformas. In: Boschi, Renato (Org.). Elites políticas e econômicas no Brasil contemporâneo: a desconstrução da ordem corporativa e o papel do legislativo no cenário pós-reformas. Fundação Konrad Adenauer, 2000. 
DoBrowolski, Sílvio. Notas sobre a atuação dos grupos sociais no cenário político. Revista de Informação Legislativa, Ano 22, n. 87, Brasília, 1985.

EgdeLL, Janet M.; Thomson, Kenneth J. The influence of UK NGOs on the common agricultural policy. Journal of Common Market Studies, v. 37, n. 1, 1999.

Epstein, Leon D. Political parties in western democracies. New Brunswick \& London, Transaction Books, 1982.

Evans, Diana. Before the roll call: interest group lobbying and public policy outcomes in house committees. Political Research Quarterly, v. 49, n. 2, 1996.

Figueiredo, John M. de; TILleR, Emerson H. Organizing and engaging in nonmarket activity: a transactional analysis of corporate lobbying at the federal communication commission. Artigo apresentado no encontro da Associação Americana de Ciência Política realizado em Atlanta, Geórgia, 1999.

FURLONG, Scott R. Interest group influence on rule making. Administration \& Society, v. 29, n. 3, 1997.

GalaskiEWICZ, Joseph. Interest group politics from a comparative perspective. Urban Affairs Quarterly, v. 16, n. 3, 1981.

Graziano, Luigi. O lobby e o interesse público. Revista Brasileira de Ciências Sociais, v. 12, n. 35, 1997.

Gros, Denise B. Liberalismo, empresariado e ação política na Nova República. In: Diniz, Eli (Org.). Empresários e modernização econômica: Brasil anos 90. UFSC/IDUSCON, 1993.

Heinz, John P.; Laumann, Edward O.; Nelson, Robert L.; Salisbury, Robert H. The hollow core: private interests in national policy making. Harvard University Press, 1993.

KEY, V. O. Politics parties and pressure groups. New York: Thomas Y. Crowell Company, 1944.

KInzo, Maria D’Alva Gil. Funding parties and elections in Brazil. In: BuRneLL, Peter; WarE, Alan (Eds.). Funding democratization. Manchester University Press, 1997.

LONGLEY, Lawrence. Interest group interaction in a legislative system. The Journal of Politics, v. 29, 1967.

MeYnaud, Jean. Os grupos de pressão. Publicações Europa-América, 1960. (colecção saber).

NiCOLAU, Jairo Marconi. Multipartidarismo e democracia: um estudo sobre o sistema partidário brasileiro (1985-1994). Rio de Janeiro: Editora FGV, 1996. 
OrRen, Gary R. Beyond self-interest. In: ReICH, Robert B. (Org.). The power of public ideas. Cambridge, Massachusetts: Ballinger Publishing Company, 1988.

Panebianco, Angelo. Modelos de partido: organización y poder en los partidos políticos. Madrid: Editora Alianza, 1990.

PASQUINO, Gianfranco.Teoria dos grupos e grupos de pressão. In: VV.AA Curso de introdução à Ciência Política, Unidade VI. Editora da Universidade de Brasília, 1982.

PIKA, Joseph. Interest groups and the executive: presidential intervention. In: Loomis, Burdett; Cigler, Allan (Orgs.). Interest group politics. Congressional Quarterly Press, Washington, 1983.

Salisbury, Robert. Interest groups. In: Polsby, N.; Greenstein, F. (Orgs.). Handbook of political science. v. 4. Ed. Addison-Wesley Publishing Company, 1977.

SARTORI, Giovanni. Partidos e sistemas partidários. Brasília: Editora Zahar/ UNB, 1982.

SmITH, Richard A. Advocacy, interpretation and influence in the U.S. Congress. American Political Science Review, v. 78, 1984.

Interest group influence in the U.S. Congress. Legislative Studies Quarterly, v. 20, n. 1, 1995.

THOMAS, Clive S.; HREBRENAR, Ronald J. A reappraisal of interest group power in the american states. Artigo apresentado no encontro da Associação Americana de Ciência Política realizado em Atlanta, Geórgia, 1999.

Tierney, John. Organized interests and nation's capitol. In: Petracca, Mark (Org.). The politics of interests: interest groups transformed. Boulder: Westview Press, 1992.

Wootron, Graham. Grupos de interesse. Rio de Janeiro: Zahar Editores, 1972

WRIGHT, John R. Contributions, lobbying and committee voting in the U.S. house of representatives. American Political Science Review, v. 54, n. 2, 1990. 
Livraria Humanitas-Discurso

Av. Prof. Luciano Gualberto, 315 - Cid. Universitária 05508-900 - São Paulo - SP - Brasil Tel: 3091-3728 / 3091-3796
HuManitas - Distribuiçäo Rua do Lago, 717 - Cid. Universitária 05508-900 - São Paulo - SP - Brasil Telefax: 3091-4589

e-mail: pubfflch@edu.usp.br

http://www.fflch.usp.br/humanitas

Ficha técnica

Mancha $11,5 \times 20 \mathrm{~cm}$

Formato $16 \times 23 \mathrm{~cm}$

Tipologia Souvenir Lt BT

e Futura Lt BT

Papel miolo: off set $75 \mathrm{~g} / \mathrm{m}^{2}$

capa: cartão supremo $250 \mathrm{~g} / \mathrm{m}^{2}$

Impressão e acabamento Provo Gráfica Ltda.

Número de páginas 408

Tiragem 500 exemplares 